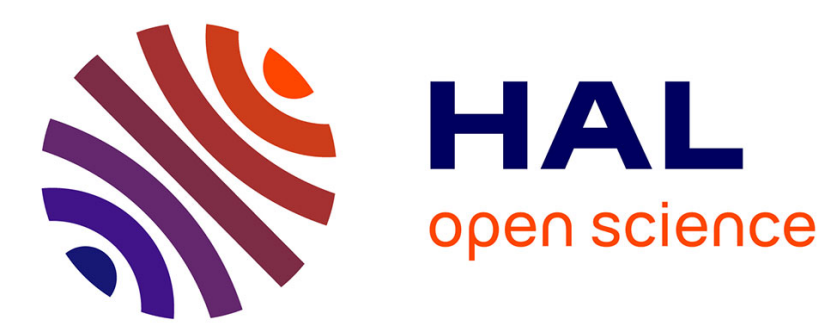

\title{
Rapidly solidified Al-Fe-Mo-Si alloys for high temperatures applications
}

\author{
M. de Macêdo, G. Michot
}

\section{To cite this version:}

M. de Macêdo, G. Michot. Rapidly solidified Al-Fe-Mo-Si alloys for high temperatures applications. Journal de Physique IV Proceedings, 1993, 03 (C7), pp.C7-235-C7-238. 10.1051/jp4:1993736 . jpa00252154

\section{HAL Id: jpa-00252154 https://hal.science/jpa-00252154}

Submitted on 1 Jan 1993

HAL is a multi-disciplinary open access archive for the deposit and dissemination of scientific research documents, whether they are published or not. The documents may come from teaching and research institutions in France or abroad, or from public or private research centers.
L'archive ouverte pluridisciplinaire HAL, est destinée au dépôt et à la diffusion de documents scientifiques de niveau recherche, publiés ou non, émanant des établissements d'enseignement et de recherche français ou étrangers, des laboratoires publics ou privés. 


\title{
Rapidly solidified Al-Fe-Mo-Si alloys for high temperatures applications
}

\author{
M.C.S. DE MACÊDO and G. MICHOT
} Laboratoire de Métallurgie Physique \& Science des Matériaux, URA 155 du CNRS, Ecole des Mines de
Nancy, Parc de Saunupt, 54042 Nancy cedex, France

\begin{abstract}
Iron solubility in aluminium can be extended through the rapid solidification route, allowing the precipitation of a high volume fraction of intermetallic phases. In the ternary $\mathrm{Al}-\mathrm{Fe}-\mathrm{Si}$ system, the observed metastable hardening phase $\mathrm{Al}_{13} \mathrm{Fe}_{3} \mathrm{Si}$ is sensitive to ripening. Thermal stability can be improved by modification of the surface energy of the precipitate, i.e. by lattice parameter variation, through addition of a transition metal: vanadium in the 8009 alloy and molybdenum in this study. The volume fraction of the silicide phase $\mathrm{Al}_{13}(\mathrm{Fe}, \mathrm{Mo})_{3} \mathrm{Si}$ can be monitered by the silicon content. With high enough Mo content, an additional hardening is expected from the $\mathrm{Al}_{12} \mathrm{Mo}$ phase. In addition to a stabilization effect of the silicide phase, molybdenum can also change the kinetic of transformation of the silicide into the coarse, brittle, equilibrium phase $\mathrm{Al}_{13} \mathrm{Fe}_{4}$. The molybdenum content was kept lower than 1 at $\%$ because the lower the liquidus temperature, the easier the atomization process. The powders are elaborated by centrifugal atomization and consolidated by hot extrusion. Phase characterization and mechanical properties in the as-extruded condition, or after high temperature exposure are reported in this study. X-rays diffraction shows mainly the presence of the silicide phase. The microstructure is so fine that only the large particles with an irregular morphology can be detected by SEM. Preliminary MET investigations of the alloy $\mathrm{Al}-2.5 \mathrm{Fe}-0.5 \mathrm{Mo}-1.0 \mathrm{Si}$ (at \%) show that these large particles are composite precipitates. We also noted some small spherical phases probably also the silicide phase. Such differences in precipitate size could be linked to differents solidification regimes. The mechanical properties of the extruded bars are tested at room temperature after 100 hours exposure at different high temperatures.
\end{abstract}

\section{INTRODUCTION}

The aluminium alloys for high temperature applications are developed by means of the rapid solidification process (1-5). One of the most attractive system is the Al-Fe-Si-Transition metal, and among them the most studied is the Al-Fe-V-Si. These alloys have elevated temperatures strengths and stability but their ductility degrades near $723 \mathrm{~K}$, due to the precipitation of the coarse phase $\mathrm{Al}_{13} \mathrm{Fe}_{4}$. But other transition metals such as Mo could present interesting properties. Skinner (1) has showed that the Al-Fe-Mo-Si system has smaller silicide dispersoid diameter and consequently higher strength than the alloys stabilized with other transition metals, even up to $500 \mathrm{~K}$. An other previous result (2) shows that in the Al-Fe-Mo-Si alloys the brittle phase $\mathrm{Al}_{13} \mathrm{Fe}_{4}$ does not precipitate even after 100 hours aging at $723 \mathrm{~K}$. For this study the powder route was preferred to melt spinning and other compositions explored.

\section{EXPERIMENTAL}

The Al-2.5Fe-0.5Mo-1.0Si (at \%) alloy is centrifugally atomized under helium gaz. The lot $50-100$ $\mu \mathrm{m}$ of the rapidly solidified powder is degassed and canned. Consolidation is achieved by hot extrusion at $673 \mathrm{~K}$ through a conical die (extrusion ratio of $22: 1$ ). The microstructures of powder particles and extruded bars are investigated by scanning electron microscopy. Transmission electron microscopy observations are achieved on nickel-plated powders. Phase identification is performed by X-Ray Co-K $\alpha$ diffraction. The extruded bars are heat treated in argon atmosphere for 100 hours at 573, 673, 753 or 823 $K$. The tensile samples ( $4 \mathrm{~mm}$ in diameter and $16 \mathrm{~mm}$ in gauge length) machined in the bars, are deformed under a strain rate of $2.6 \times 10^{-4} \mathrm{~s}^{-1}$. Complementary informations are derived from Vickers microhardness mesurements (a $100 \mathrm{gf}$ load is applied for 20 seconds). 


\section{RESULTS AND DISCUSSION \\ Microstructure}

Powder particles are spherical with either precipitate free cellular surfaces or precipitate-covered surfaces (figure 1). Observations of particles sections show that, except a few particles exhibiting only a solid solution, the same precipitates are observed in the bulk (figure 2): they seems spherical with a core different from the outside layer. Finer features are obtained by TEM (figure 3): electron diffraction failed to determine the nature of the precipitate core. However because the X-Ray diffraction pattern underlines only two phases in the as solidified condition, the $\mathrm{Al}_{13}(\mathrm{Fe}, \mathrm{Mo})_{3} \mathrm{Si}$ phase and the $\mathrm{Al}$ matrix, we assume as other authors (3), that this composite precipitate is formed by an inner quasicrystalline phase surrounded by small silicide particles of cubic structure. TEM shows two other important microstructural features: an intercellular precipitation (figure 4) resulting from segregation during the solidification and a very fine precipitation of $\mathrm{Al}_{13}(\mathrm{Fe}, \mathrm{Mo})_{3} \mathrm{Si}$ in the grain (figure 5).

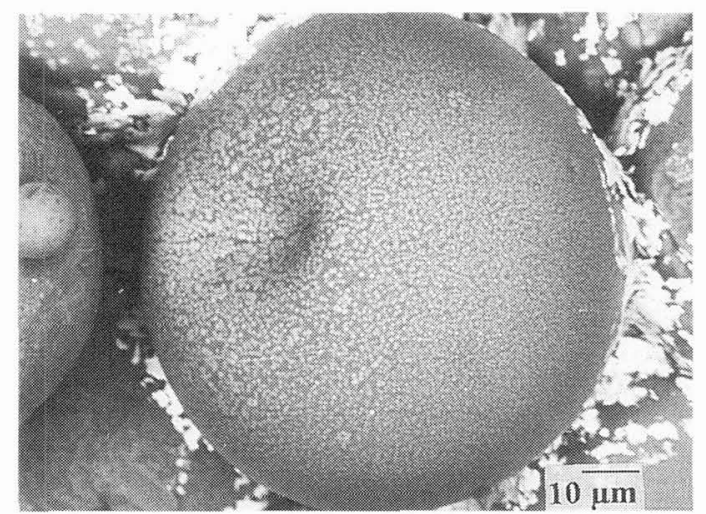

Figure 1 - As solidified powder particle with surface precipitates. (SEM).

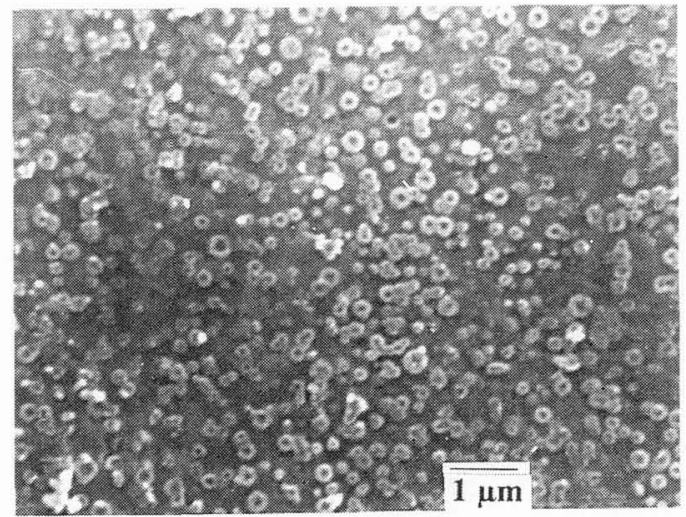

Figure 2 - Section of as solidified powder particle. Differences in contrast between the precipitates core and the outside layer are noticed. (SEM).

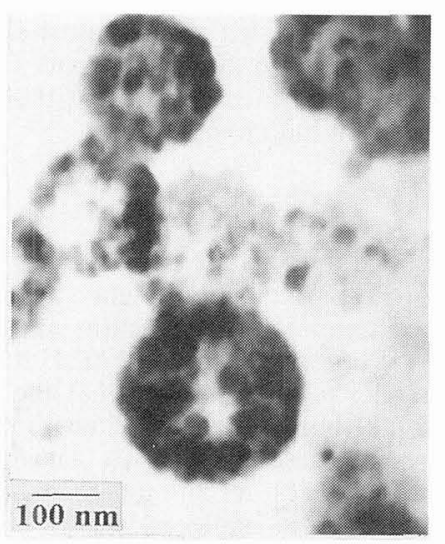

Figure 3 - As solidified powder particle showing probably composite precipitates. (TEM).

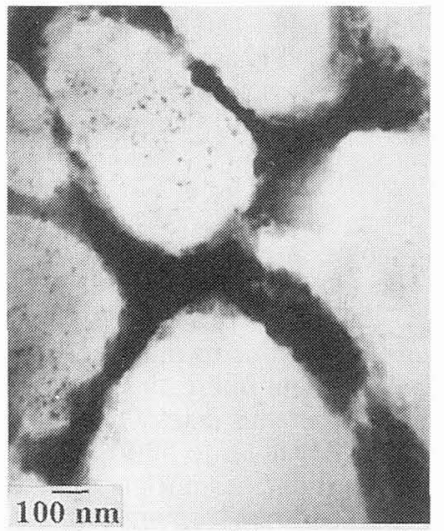

Figure 4 - As solidified powder particle showing intercellular precipitation. (TEM).

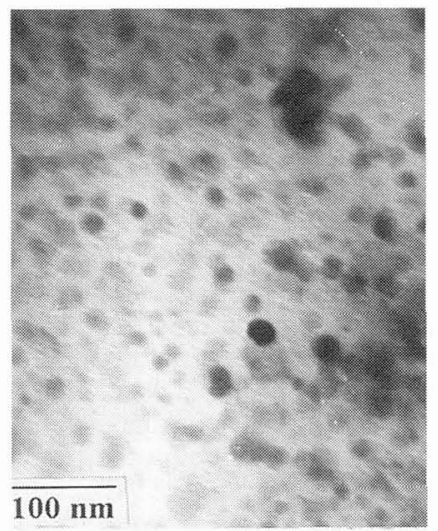

Figure 5 - As solidified powder particle. Very fine silicide precipitates are seen. (TEM).

The composite precipitates are still present after extrusion (figure 6). A slight coarsening could have occurred during extrusion. The microstructure is not completely homogeneous, some precipitate rich zones are observed (figure 7). High temperature exposure for 100 hours does not change the microstructure as observed by SEM of the powder or of the consolidated bar up to $723 \mathrm{~K}$ : indeed X-ray diffraction shows a very limited precipitation of the $\mathrm{Al}_{12} \mathrm{Mo}$. In return, at $823 \mathrm{~K}$ a considerable amount of this phase is detected. A more detailed study of the silicide coarsening and $\mathrm{Al}_{12} \mathrm{Mo}$ precipitation needs additional TEM investigation. 


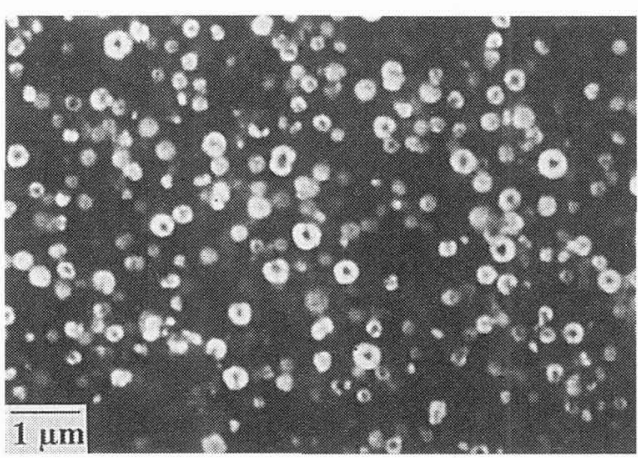

Figure 6 - As extruded condition. Transversal section. The composite precipitates are still presents. (SEM).

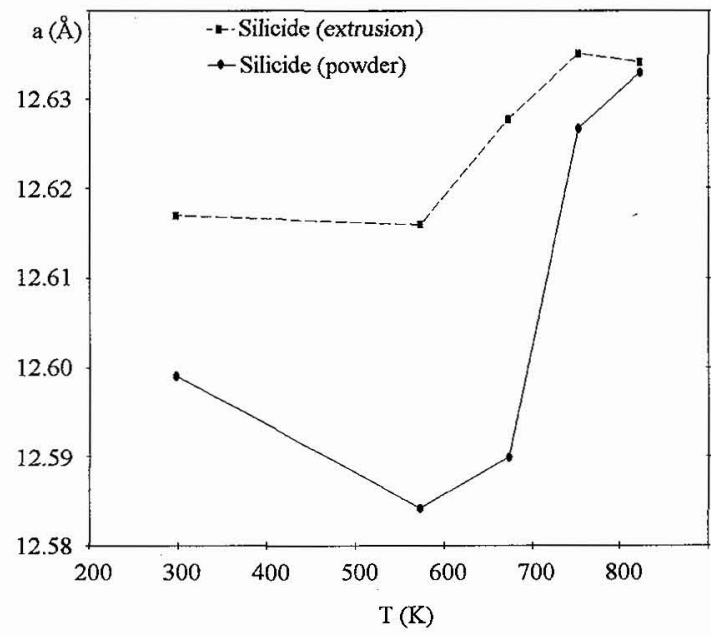

a)

Figure 8 - Variation of the lattice parameter with the heat treatment temperature: a) silicide $\mathrm{Al}_{13}(\mathrm{Fe}, \mathrm{Mo})_{3} \mathrm{Si}$ and b) $\mathrm{Al}$ matrix.

Even if the thermal stability of the silicide phase is excellent some diffusion must take place during high temperature exposure. This fact is underlined by the evolution of the parameter of the cubic phases (silicide, fig. 8.a and matrix, fig. 8.b): the larger variation observed on the powder indicates that some stoichiometric change of the silicide phase occurs during extrusion. The variation of the matrix parameter observed at high temperature $(>753 \mathrm{~K})$ ilustrates the probable release of Mo atoms from solid solution leading to $\mathrm{Al}_{12} \mathrm{Mo}$ precipitation.

\section{Mechanical Properties}

The alloy composition was chosen in order to obtain a volume fraction of $16 \%$ silicides and $4 \%$ $\mathrm{Al}_{12} \mathrm{Mo}$ phase. As previously mentioned, there is no $\mathrm{Al}_{12} \mathrm{Mo}$ precipitation in the as extruded condition. The tensile properties and the density of our alloy, in the as extruded condition, are very similar to those of the FVS0611 alloy (4), (see table I). In that way we think that the Mo which is in solid solution has not a strong hardening effect. As can be seen in figures 9 and 10 the mechanical properties are relatively constant up to $753 \mathrm{~K}$.

Microhardness does not vary too much up to $673 \mathrm{~K}$. Above this temperature, the hardness decrease may be due to the coarsening of the silicide phase while the further hardness increase (fig. 9) could be related to the strong $\mathrm{Al}_{12} \mathrm{Mo}$ precipitation, as detected by $\mathrm{X}$-Ray diffraction. 


\begin{tabular}{|c|c|c|}
\hline Alloy & Al-2.5Fe-0.8Mo-1.0Si & FVS0611 \\
\hline Fe (at \%) & 2.5 & 3.3 \\
\hline Si (at $\%)$ & 1.0 & 1.3 \\
\hline Mo or V (at\%) & 0.8 & 0.3 \\
\hline Al (at\%) & Balance & Balance \\
\hline Density (gcm $\left.{ }^{-3}\right)$ & 2.87 & 2.83 \\
\hline UTS (MPa) & 305 & 311 \\
\hline Yield strength (MPa) & 247 & 258 \\
\hline Elongation (\%) & 17.8 & 22.3 \\
\hline
\end{tabular}

Table I - Composition, density and tensile properties comparison between $\mathrm{Al}-2.5 \mathrm{Fe}-0.8 \mathrm{Mo}-1.0 \mathrm{Si}$ and FVS061 1 (data from (4)) in the as consolidated condition.

A good level of ductility is maintened up to $823 \mathrm{~K}$ : that confirms that molybdenum delays the precipitation of the embrittling $\mathrm{Al}_{13} \mathrm{Fe}_{4}$ phase (2). An other interesting feature of molybdenum could be to pin the grain boundary by $\mathrm{Al}_{12} \mathrm{Mo}$ precipitation, as observed in binary Al-Mo alloys (6), avoiding recrystallization. The $0.2 \%$ yield strength and the ultimate tensile stress have the same behaviour after 100 hours of high temperature exposure as the Al-Fe-V-Si alloys, but because of the lower volume fraction of precipitates $(16 \%$ of silicides against $24 \%$ ) and the choice of the elaboration route (centrifugal atomization instead of melt spinning) slightly lower performances are noticed, compared to Al-Fe-V-Si (5).

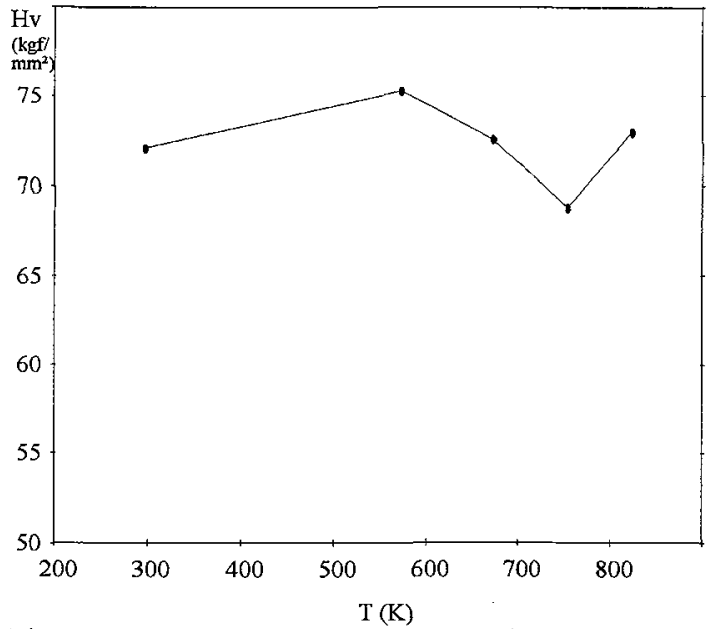

Figure 9 - Room temperature microhardness Vickers variation with exposure temperature $(100$ hours exposure).

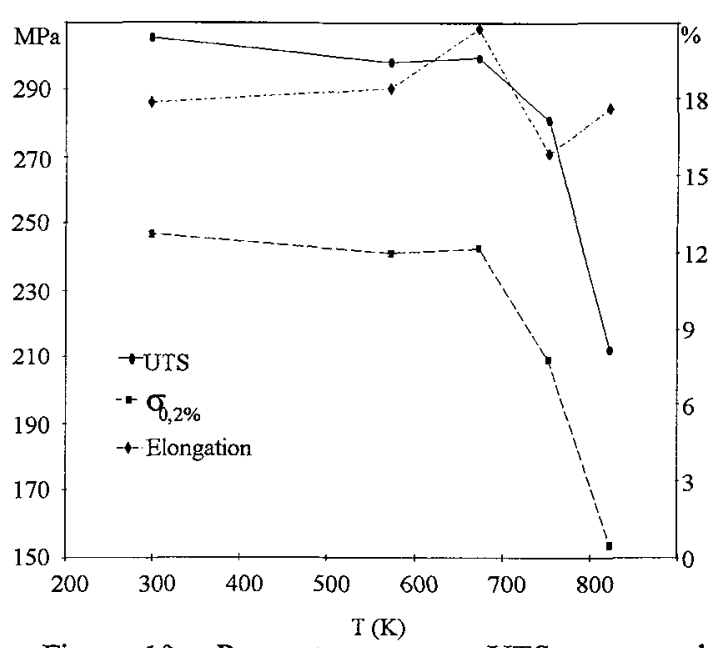

Figure 10 - Room temperature UTS, $\sigma_{0.2 \%}$ and elongation variation with exposure temperature (100 hours exposure).

\section{CONCLUSIONS}

The performances of such Al-Fe-Mo-Si alloys, elaborated through the powder route, therefore bypassing the comminuting step of the ribbon, seem interesting. Their ductility level is maintened up to $823 \mathrm{~K}$, good formability could be expected. However it must be checked that this alloy has not to face the same strain rate sensitivity problems as the 8009 alloy.

\section{REFERENCES}

1) SKINNER D.J., BYE R. L., RAYBOULD D., BROWN A.M. and ZEDALIS M.S., Processing of Structural Metals by Rapid Solidification, ed. F.H. Froes and S.J. Savage, (1986), 291.

2) VASUDEVAN V.K. and FRASER H.L., Script. Met. 21, (1987), 1105.

3) SRIVASTAVA A.K. and RANGANATHAN S., Script. Met. et Material. 27, (1992), 1241.

4) GILMAN P., Defense \& Aerospace, august 1990, 504.

5) SKINNER D.J., BYE R. L., RAYBOULD D. and BROWN A.M., Script. Met. 20, (1986), 867.

6) LOGAN E.A., PRATT J.N. and LORETTO M.H., Mat. Sci. and Technology, february 1989, $\underline{5}, 123$. 